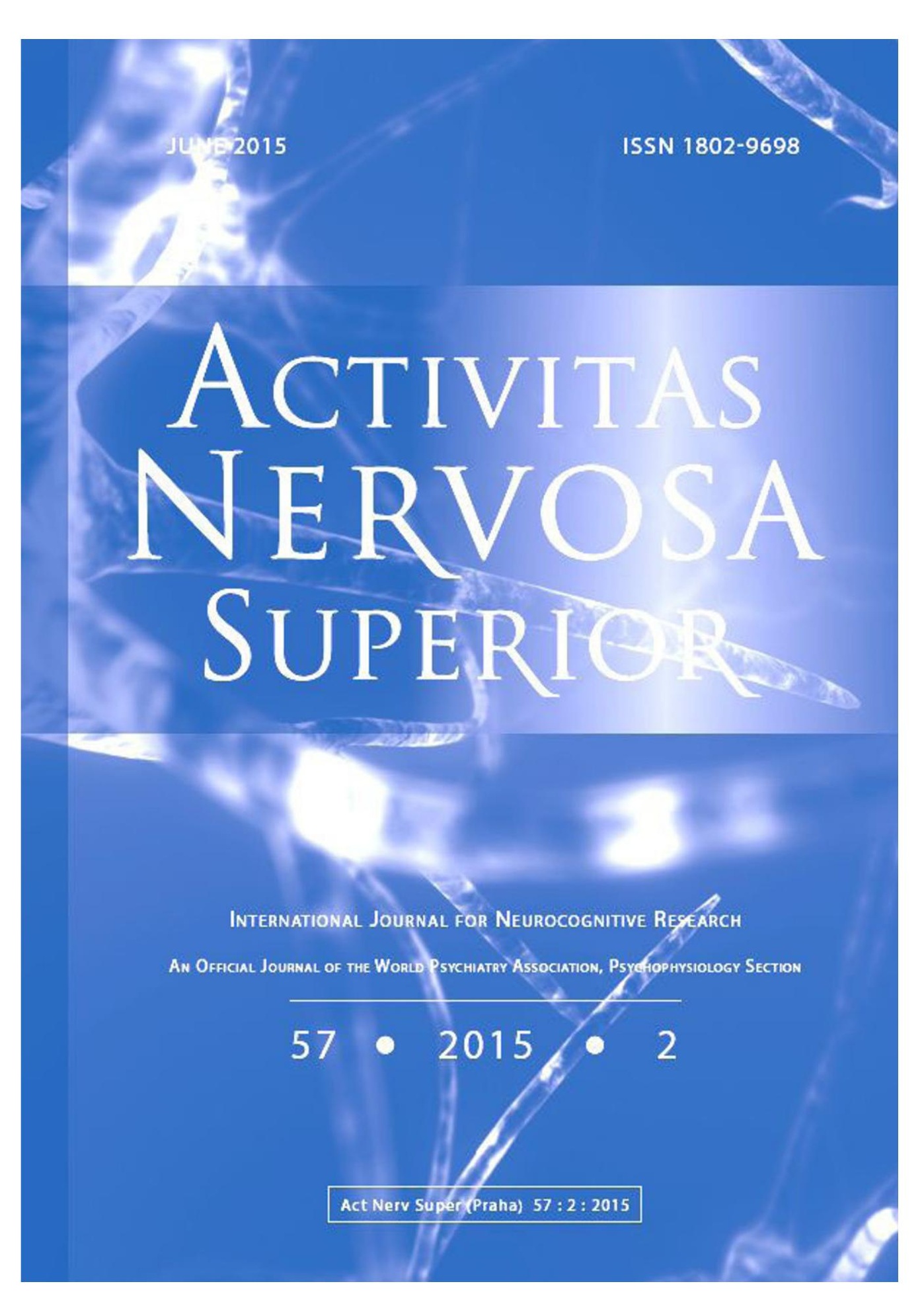

\title{
TRAUMA, DISSOCIATION AND SYNTHETIC METACOGNITION IN SCHIZOPHRENIA
}

\author{
Ondrej Pec ${ }^{\star 1,2}$, Petr Bob ${ }^{1}$, Paul H. Lysaker ${ }^{3,4}$ \\ ${ }^{1}$ Center for Neuropsychiatric Research of Traumatic Stress, Department of Psychiatry and UHSL, First Faculty of \\ Medicine, Charles University, Prague, Czech Republic \\ 2ESET, Psychotherapeutic and Psychosomatic Clinic, Prague, Czech Republic \\ 3 Roudebush VA Medical Center, Indianapolis, United States \\ 4Indiana University School of Medicine, Department of Psychiatry, Indianapolis, Indiana, United States
}

\begin{abstract}
Both childhood trauma and dissociation are associated with schizophrenia. More rudimentary form of dissociation known already from Eugen Bleuler as splitting of association is theoretically close to the modern concept of synthetic metacognition in schizophrenia. The synthetic metacognition as a psychological process is described as a capability to synthesize intentions, thoughts, feelings, and connections between events, and to integrate them into larger complex representations of self and others. Disturbed synthetic metacognition was found in early as well as in late forms of schizophrenia and has its typical formula. Deficit of synthetic metacognition is related to symptoms of schizophrenia and psychosocial functions. Synthetic metacognition is measurable by analyzing discourse using standardized procedures. The level of metacognition is assessed from the sample of narrative on the basis of the Metacognitive Assessment Scale - Abbreviated (MAS-A). Psychotherapies focused on strengthening of metacognitive functions concentrate on integration of fragmented mental content or on promoting of formation of stable mental representations in this disorder.
\end{abstract}

Key words: Schizophrenia; Metacognition; Trauma; Dissociation; Splitting; Psychotherapy

\section{INTRODUCTION}

Research conducted over the last decade has made great progress in the field of childhood trauma and dissociation in schizophrenia. It has made gradually clear that childhood traumatic experiences represent a crucial risk factor for the development of schizophrenia. The recent research shows that environmental factors could be more even powerful predictor of schizophrenia than genetic risk factors (Fisher et al., 2014; Stepniak et al., 2014).

Recently, similarly to trauma, and dissociation, also a great attention has been paid in research to metacognition, especially in a form of synthetic metacognition. Both research fields are interrelated and represent a potential for development of effective therapeutic methods.

\footnotetext{
"Correspondence to: Ondrej Pec, email: eset.pec@volny.cz

Received May 12, 2015; accepted May 29, 2015; Act Nerv Super 57(2), 59-70; ISSN-1802-9698
} 


\section{TRAUMA AND DISSOCIATION}

Childhood trauma has been associated in many studies with psychosis and schizophrenia. Read et al. (2005) found in their review that a majority of female patients $(69 \%)$ as well as male patients $(59 \%)$ underwent child sexual abuse or child physical abuse. These patients also had more difficult course of the disease. Child abuse was specifically associated with positive symptoms and namely hallucinations (Perona-Garcelan et al., 2008; Read et al., 2005; Ross et al., 1994), higher levels of anxiety (Lysaker \& Salyers, 2007), suicidal behavior (Roy, 2005), poorer psychosocial functioning and work performance (Lysaker et al., 2001, Lysaker et al., 2004). Janssen et al. (2004) showed in a prospective study that childhood abuse is a risk factor for becoming psychotic in a later time and this relationship is dose-dependent. However, studies researching a type of trauma in psychosis and it's relevance to symptoms gives also conflicting results. Ucok \& Bikmaz (2007) in a sample of first-epizode schizophrenia found more patients with previous emotional abuse, than with childhood sexual or physical abuse. In a general population study of Berenbaum et al. (2003) childhood neglect provided better prediction of schizotypal traits than the latter both types of trauma. A recent study of Larrson et al. (2013) indicates that patients with schizophrenia spectrum disorders more frequently experienced physical abuse or physical neglect than patients with affective disorder and that occurrence of trauma is dose-related to severity of symptoms and psychosocial functioning. Similarly, Gil et al. (2009) found that physical neglect had an effect on adult functionality. On the other hand, other studies didn't show a significant relevance between trauma and severity of symptoms (Fisher et al., 2011; Vogel et al., 2006). Moreover, beyond childhood trauma also symptoms of psychosis or an experience with psychiatric services, predominantly hospitalization, may play a causative role of trauma for development of comorbid PTSD (Morrison et al., 2003) and chronic schizophrenia patients exhibit clinically significant trauma symptoms (Lysaker \& LaRocco, 2008).

Since Zubin \& Spring (1977) vulnerability/stress model researchers have been making efforts to create an explanatory model integrating the psychosocial and biological factors including trauma and stress in schizophrenia. Walker \& Diforio (1997) proposed "a neural diathesis-stress model" and suggests that trauma, stigma, poverty, isolation, and attachment patterns play a significant role in the development of the neurocognitive abnormalities of schizophrenia. They supposed that stress worsens symptoms and that the diathesis is associated with a heightened response to stressors which may have the augmenting effect of the HPA axis on dopamine synthesis and receptors that in turn may lead to abnormal dopamine receptor functioning. In this connection, Read et al. (2001) developed "a traumagenic neurodevelopmental model" that proposes that together with a genetic deficit also early adverse life events create a predisposing vulnerability in the form of hypersensitivity to stress that leads to typical neuroanatomical, cognitive or symptomatic features of schizophrenia. Barker et al. (2015) suggests that a pathway from childhood maltreatment to psychosis leads via HPA axis hyperactivation, reduced hippocampal BDNF and oxytocin levels, and NMDA hypoactivation by glutamate to decreased hippocampal volume and increased mesolimbic dopamine.

In the context of stress/diathesis models, trauma has been studied in a close relationship to dissociation in schizophrenia. Across research reports chronic complex dissociation ranges between $25-40 \%$ in patients treated for schizophrenia (Ross, 2009). Dissociation has been considered to be associated with childhood trauma in many studies and a subgroup of schizophrenia patients with more frequent childhood trauma history and more severe symptoms of dissociation has been identified (Moskowitz et al , 2009; Sar et al., 2010; Schafer et al., 2012). Ross (2009) proposed a separated dissociative type of schizophrenia characterized by a history of severe chronic childhood trauma, prominent dissociative symptoms and a lack of cognitive disorganization or thought disorder. Dissociation is in general linked to positive symptoms of schizophrenia (Spitzer et al., 1997), but dissociative amnesia is related to 
negative symptoms (Vogel et al., 2009a). In respect to a type of trauma, dissociation has been found related to emotional and physical abuse (Schafer et al., 2012), physical abuse and neglect (Sar et al., 2010), and childhood neglect (Vogel et al., 2009b). Dissociation is probably state related and diminishes in a course of treatment of acute in-patients (Schafer et al., 2012).

\section{DISSOCIATION, SPLITTING AND METACOGNITION}

In spite of many findings showing a connection between trauma and dissociation, a significant portion of dissociation in schizophrenia seems to be independent of previous trauma history. Vogel et al. (2006) found that even patients without a history of trauma or posttraumatic symptoms can elevate a level of dissociation on the DES scale and in a later study (Vogel et al., $2009 b$ ) it has been showed that dissociation has a more proximal impact on schizophrenia symptoms then trauma history. Moreover, a worse capability to discriminate negative emotion in schizophrenia and schizoafective patients is probably associated with amnestic dissociation and therefore with functional deficit in these disorders (Renard et al., 2012). All these recent findings show that dissociation is not only related to previous trauma history and that it may contribute to characteristic feature of schizophrenia, perhaps as a psychological mechanism of defense for mitigation of strong disorganizing affects or inner conflicts (Giese et al., 1997; Vogel et al., 2009b). But it seems that dissociation doesn't serve effectively in this way in psychoses.

Although scores of dissociation in schizophrenia are higher than in healthy people they are lower than in other psychiatric disorders (borderline personality disorder, dissociative disorders) (Putnam et al., 1996). On top of that, in dissociative disorders, qualitatively in comparison to schizophrenia, there is a maintained reality testing and the positive psychotic symptoms are better demarcated from stressful experiences like anxiety or intra-psychic tension. Positive symptoms are less rudimentary and more differentiated (Moskowitz et al., 2009; Nurcombe et al., 2009). Consequently, people with psychosis then could be described as "less capable dissociators" whose "capacity to handle traumatic or highly emotional experiences via dissociative mechanism is limited" (Moskowitz et al., 2009, p.528-529). These more rudimental forms of disintegration are already known from Bleuler (1911/1950) who beyond "splitting of psychic functions" and "splitting into different persons" where complex psychic structures disintegrate described also associative splitting or "loosening of associations", when the normal pathways of associations loose their cohesiveness which leads to displacements, condensations, confusions, generalizations, clang-associations, illogical thinking, or incoherence. He considered it as a basic factor in pathogenesis of the disease.

The idea of Bleuler's schizophrenic splitting has its predecessors and followers. Bleuler followed up on work of Jung (1909). Jung (1909) proposed that any association is related to a complex mental aggregate of an experience connecting emotional, episodic and semantic memories. Among these complexes the ego complex is the highest psychic instance having inhibiting impact on other complexes until a strong affect (for instance fear) enables creating of a new emotionally charged complex which even after disappearing of this affect persists in a form of complex sensitiveness (readiness of the complex to re-appear in a presence of much weaker stimuli than previously). In that way the complex can take a "relatively independent position to the ego complex" (p.44) and loose cohesiveness typical for larger ideas about self and other objects. The line of Jung's thinking is built on previous tradition of psychopathology in work of Janet, Masselon, Pelletier, or Weygandt. For instance Pelletier described "shallow flow of associations" in schizophrenia with absence of directing principle in consciousness together with a loss of ordering of its elements or Weygandt supposed "apperceptive dementia" as a disorder of synthesis of various psychic functions in schizophrenia (Jung, 1909, p.10-11).

After Bleuler the concept of schizophrenic splitting was elaborated by other authors mainly from the circle of psychoanalysts with a conclusion that it has a form of fragmentation where 
splits occurs simultaneously (fractured actions, affects, raw drives, perceptions, memories and fantasy elaborations), lacks reality testing as well as identification of subjectivity (Blatt \& Auerbach, 2001; Lustman, 1977). It is linked to inability to appropriately differentiate and distinguish between self and non-self as an agent of an internal experience (Anzieu, 1993; Bion, 1957; Bleger, 1974; Ogden, 1989). Moreover, dissociated part selves can eliminate psychic elements from the executive self which could result in impoverishment of thinking or abulia (Bion, 1957; Hinshelwood, 2008; Read et al., 2005) and thus this undifferentiated mental state forms a basic deficit in the development of cognitive functions and perceptual awareness (Grotstein, 1977a, 1977b).

In the last decade the Bleuler's concept of splitting is increasingly discussed as closely linked to the mind's metacognitive abilities (Lysaker et al., 2013). As indicated by Moskowitz (2008), when Bleuler proposed disturbances of associations as the core feature of schizophrenia he did not refer merely to confusion due to the intrusion of unrelated ideas into thought but to the fundamental loss of the ability to "associational synthesis" (p. 44) which reduced the understanding of a person with his own body to a set of fragments which no longer served as a guide for goal directed activity. Bleuler supposed that this lack of synthesis had a somatic origin, but it could also be used as a proximate cause of dysfunction. Bleuler described detailed examples of schizophrenia patients no longer able to exert social or vocational functions and their loss of the ability to synthesize associations into larger images of oneself and others which then results in metacognitive dysfunction (Lysaker et al., 2013). In that way we can regard metacognition as a reciprocal function to splitting.

\section{SYNTHETIC METACOGNITION AND SCHIZOPHRENIA}

Metacognition as a psychological process is defined as a spectrum of mental activities that involves thinking about thinking, ranging from discrete mental activities such as thinking about a specific isolated thought to more synthetic acts in which context of intentions, thoughts, feelings, and connections between events, are integrated into larger complex representations of self and others including also a reflection about that larger representation (Lysaker et al., 2013). Metacognition in its synthetic form implies how basic elements of experience are recognized and then synthesized into complex wholes and in that way synthetic metacognitive acts also affect life in a different manner giving meaning to events, and thus, supplying reasons why to carry out a certain act and how to resolve dilemmas in the realm of the unique psychology of oneself and the others. Metacognition is related to the concept of mentalization (Bateman \& Fonagy, 2006), though the latter construct considers that disruptions of the above mentioned psychological processes happen in the context of disturbed attachment. Synthetic metacognitive activities allow persons to form evolving and flexible representations for themselves and others and thus they form a basis for the ability to regulate affect and behavior (Lysaker et al., 2013).

There are different patterns of metacognitive deficits in patients with different types of psychopathology, whether these are personality disorders (Semerari et al., 2005), psychosis (Brüne, 2005), or Asperger syndrom (Frith \& Vignemont, 2005). Concerning schizophrenia, impaired metacognition has been found in both earlier and later forms of the illness (Vohs et al., 2014). Disruption of metacognition is specific for schizophrenia in comparison to other non-psychotic adverse conditions as HIV-positive patients (Lysaker et al., 2012). Disturbed metacognition is related with negative symptoms (McLeod et al., 2014; Nicolo et al., 2012) and recent studies show that difficulties with metacognitive processing might be important determiants for expression of negative symptoms from early stage of development of psychosis. Metacognitive mastery, in other words an ability to use knowledge about oneself, other people, and context of a situation to cope with mental health problems, has close relationship with intrinstic motivation in schizophrenia (Vohs \& Lysaker, 2014) and both qualities predict learning ability (Tas et al., 2012). Metacognitive mastery shows a similar 
connection also in relation to functional competence (Lysaker et al., 2011b; Lysaker et al., 2011d) and moderates influence of neurocognitive deficits on social functions (Lysaker et al., 2010c). A similar finding is that better self-reflection prospectively predicts keeping a job position in schizophrenic patients (Lysaker et al., 2010a).

The link between synthetic metacognition and clinical and functional characteristics in schizophrenia suggests that synthetic metacognition could play a mediating and moderating role between neurocognitive deficits, symptoms, and psychological factors and thus influence the real impact of schizophrenia on social adaptation of patients (Lysaker et al., 2013).

\section{ASSESSMENT OF SYNTHETIC METACOGNITION}

Synthetic metacognition is assessed by analyzing discourse with use of a standardized method. A basis for the assessment is a spontaneously generated speech sample in which persons discuss their lives and personal understanding of the situations in which they found themselves. The speech sample is obtained through a semi-structured interview called the Indiana Psychiatry Illness Interview (IPII). On the basis of IPII an interviewer learns from the investigated person what he thinks or who they are as a person and what are their experience with psychiatric challenges. This will allow that person to tell his life story and create opportunities for investigated persons to spontaneously reveal how they think about themselves. To quantify the capacity for synthetic metacognition within a narrative generated by the IPII the Metacognition Assessment Scale - Abbreviated [MAS-A] is used (Lysaker et al., 2005a). The MAS-A contains four scales. In each scale higher scores reflect abilities to perform increasingly complex synthetic acts. The original unabridged scale that measures metacognition (MAS; Semerari et al., 2003) was designed for viewing metacognitive changes based on transcripts of psychotherapy sessions in persons with personality disorders.

The narrative of the investigated persons created on the basis IPII interview is stored by audio recording which is further transcribed into a text format. Then an evaluator assesses the proper level of metacognition. Evaluators undergo a special training, during which they learn to evaluate transcripts of model narratives and consult their evaluation with supervision evaluators. The evaluator reads the full transcript and assigns for each subscale one point for each function in which considers that investigated person has fulfilled within a range of the given transcript. In this way, a score is determined for each subscale that estimates the level of metacognition achieved in the corresponding domain.

For better understanding in the following text we provide further description of the semistructured interview IPII and the assessment scale MAS-A.

\section{THE INDIANA PSYCHIATRIC ILLNESS INTERVIEW- IPII}

The Indiana Psychiatric Illness Interview - IPII) (Lysaker et al., 2002) is a semistructured interview which is conceptually divided into five sections. At first, after establishing contact investigated persons are asked to tell the story of their lives as detailed as possible. In the second step, these persons are asked to think about their mental illness and about how they understand it. Another question seeks to ascertain how their health status is reflected in their interpersonal and psychological life. Furthermore, the persons are asked whether and how their health affects their lives and how in turn they can affect their health. They are also asked about whether the disease is affected by other people and to which extent other people are affected by their disease. The last question focuses on their expectations for the future, what do they think that will stay the same and what will change in the future, again in the area of interpersonal and psychological functions. Interviewer IPII doesn't ask questions specifically on the circumstances, which are not included in the questionnaire, but he may require an explanation, if he perceives ambiguities (in a non-directive way). The interviewer also must 
not offer such comments, by which he would help an investigated person to clarify their views or which give structure to the story, which he considers as disorganized.

\section{THE METACOGNITION ASSESSMENT SCALE - ABBREVIATED [MAS-A]}

MAS and MAS-A contain four subscales: "self-reflection" or the ability to think about own mental states; "understanding the other's minds," or the ability to think about the mental states of other people; "decentralization" or the understanding of the world that exists in the presence of other people who have independent motives; and "mastery" or the ability to use effective strategies to cope with mental health problems and related emotional moods. Each subscale consists of a series of items with defined criteria for compliance with certain metacognitive abilities. The items are arranged hierarchically in terms of difficulty of metacognitive capacity. In each subscale thus higher scores indicate greater ability to perform complex synthetic mental activity.

The individual subscales describe not only components of the evaluation tool, but also characterize the content of the synthetic metacognition in general; therefore we show them in detail.

The subscale "self-reflection" measures own ability to create representations of the own person that are progressively more complex and more integrated. It starts from experience and recognition of mental events inside own minds and continues to communicate complex personal stories that provide a picture of the storytellers made up of a complex series of interacting intentions, thoughts and feelings. Lower scores reflect only the ability to identify thoughts as their own and the ability to distinguish that another person has different cognitive operations and emotions. Higher scores indicate the ability to understand the subjectivity of their own thinking and to distinguish between fantasy and reality. The highest scores indicate understanding of the relationship between thoughts, emotions and other social or interpersonal variables in a range of different life events.

The subscale referred to as "understanding the other's minds" measures the individual's ability to create progressively more complex and integrated representation of an another person. It refers to the knowledge of a certain persons or a familiar group such as family. Lower levels of evaluation are characterized by the knowledge that in other people there are some mental processes, or that they have their own thoughts. The individual levels of rating then proceed to the ability to recognize that other people have different kinds of cognitive operations and emotions, and to the ability to design complex reasoning about other people's lives. Higher scores also show the capacity to understand the relationships between thoughts, emotions, behavior and developmental or interpersonal variables.

The subscale termed "decentralization" measures an individual's ability to recognize that other people live their own lives, which may indeed be intertwined with the investigated person, but they are involved in their own interests more than the interests of the examined person, and that therefore the investigated person is not the center of life of other people. This subscale reflects the ability of the investigated persons to place thoughts about themselves into the wider social world. At lower levels of the evaluation the investigated persons perceive that all events exist in relation to them, while at higher levels the participants understand that there are different proper perspectives on the same thing and that everyone respect his own way of life.

The last subscale, which is called "mastery", measures ability of an individual to use metacognitive knowledge of himself and other people to manage mental health problems, which are the source his difficulties. This subscale is not intended to measure the ability to solve general problems, but rather it is a measure of the ability to use the metacognitive knowledge, that are assessed in the other subscales. Here, however, it is specifically aimed at dealing with problems related to mental health. 
The instrument MAS-A shows a good inter-rater reliability and a stable test-retest reliability (Lysaker et al. 2008). The validity was verified by correlations of individual subscales MAS-A with other relevant instruments (Lysaker et al., 2005a, 2007, 2010b, 2011b, c). MAS-A has been also adapted to the Italian population with similar psychometric properties as the original instrument (Nicolò et al., 2012).

\section{CHANGING DISSOCIATION AND SYNTHETIC METACOGNITION IN PSYCHOTHERAPY}

The relationship between synthetic metacognition and schizophrenic symptoms or dysfunctions and theoretical relatedness to dissociation and splitting suggest that patients with schizophrenia may need specific support, preferably in a form of psychotherapy, to integrate information when creating personal insight and developing thought processes for coping with problems of their lives. The improvement of social adaptation capabilities in relation to strengthening of the metacognitive functions is documented by recent findings of correlations between synthetic metacognition and some psychological characteristics of schizophrenia: a subjective perception of recovery from illness (Kukla et al., 2013), a resistance to stigma (Nabors et al., 2014) or an ability to create interpersonal relationships (Lysaker et al, 2011b).

In recent decades, there were new trends in psychotherapy of schizophrenia, which focused on the integration of fragmented mental content or to promote formation of stable mental representations. Such examples are complex forms of cognitive remediation (Roder, Mueller, \& Schmidt, 2011), supportive psychodynamic approaches (Rosenbaum et al., 2012), psychoanalytic psychodrama (Corcos et al., 2012) or self-complexity (Martens, 2009). In addition, there are also psychotherapeutic approaches aimed directly at improving synthetic metacognition (Bargenquast et al., 2015; Brent, 2009; Hasson-Ohayon, 2012; Hills et al., 2005; Lysaker et al., 2011a; Van Donkersgoed et al., 2014). For these psychotherapeutic approaches it is possible to observe an increase of metacognition during psychotherapy using the scale MAS-A (Lysaker, Buck, \& Ringer, 2007; Lysaker et al., 2005b). Evaluation using MAS-A may even direct interventions during individual psychotherapy (Lysaker et al., 2011a). In addition, evaluation of metacognition may predict the development of therapeutic alliance in psychotherapy (Davis, Eicher, \& Lysaker, 2011).

\section{CONCLUSION}

The possibility that childhood trauma and dissociation, especially in its more rudimental form of splitting of association described already by E.Bleuler, have a causative effect for schizophrenia opens an important space for studying synthetic metacognition which is theoretically close to the concept of the splitting of association and could be considered as its reciprocal function. Also over the last decade it has been shown that synthetic metacognition has a close relationship to symptoms, dysfunctions and other characteristics on the mental level in schizophrenia. For the measurement of synthetic metacognition in research as well as in clinical practice the assessment tool MAS-A with proven psychometric properties has been developed. From clinical perspective there is a chance to make use of psychotherapeutic approaches strengthening synthetic metacognition and to develop novel methods specially focused on its improvement aiming to foster recovery in schizophrenia.

\section{ACKNOWLEDGEMENTS}

This study was supported by research grant provided by Charles University (PRVOUK). 


\section{REFERENCES}

Anzieu, D. (1993). Autistic Phenomena and the Skin Ego. Psychoanalytic Inquiry, 13, 42-48.

Bargenquast, R., Schweitzer, R.D., Drake, S. (2015). Reawakening reflective capacity in the psychotherapy of schizophrenia: a case study. Journal of Clinical Psychology, 71, 136-45.

Barker, V., Gumley, A., Schwannauer, M., \& Lawrie, S.M. (2015). An integrated biopsychosocial model of childhood maltreatment and psychosis. British Journal of Psychiatry, 206, 177-180.

Bateman, A.W., \& Fonagy, P. (2006). Mentalization-Based Treatment for Borderline Personality Disorder: A Practical Guide. Oxford: Oxford University Press.

Berenbaum, H., Valera, E., \& Kerns, J. (2003). Psychological trauma and schizotypal symptoms. Schizophrenia Bulletin, 29, 143-152.

Bion, W.R. (1957). Differentiation of the Psychotic from the Non-Psychotic Personalities. International Journal of Psychoanalysis, 38, 266-275.

Blatt, S.J., \& Auerbach, J.S. (2001). Mental Representation, Severe Psychopathology, and the Therapeutic Process. Journal of the American Psychoanalytic Association, 49, 113-159.

Bleger, J. (1974). Schizophrenia, Autisms, and Symbiosis. Contemporary Psychoanalysis, 10, 19-25.

Bleuler, E. (1911/1950). Dementia praecox or the group of schizophrenias. Zinkin, J, (Trans.). New York: International Universities Press.

Brent, B. (2009). Mentalization based psychodynamic psychotherapy for psychosis. Journal of Clinical Psychology, 65, 803-814.

Brüne, M. (2005). Theory of mind in schizophrenia: A review of the literature. Schizophrenia Bulletin, 31, 21-42.

Corcos, M., Jeammet, P., Morel, A., Chabert, C., \& De Lara, A.C. (2012). Current developments in the practice of individual psychoanalytic psychodrama in France. International Journal of Psychoanalysis, 93,561-84.

Davis, L.W., Eicher, A.C., \& Lysaker, P.H. (2011). Metacognition as a predictor of therapeutic alliance over 26 weeks of psychotherapy in schizophrenia. Schizophrenia Research, 129, 85-90.

Fisher, H.L. Craig, T.K., Fearon, P., Morgan, K., Dazzan, P., Lappin, J., Hutchinson, G., Doody, G.A., Jones, P.B., McGuffin, P., Murray, R.M., Leff, J., \& Morgan, C. (2011). Reliability and Comparability of Psychosis Patients' Retrospective Reports of Childhood Abuse. Schizophrenia Bulletin, 37, 546-553.

Fisher, H. L., McGuffin, P., Boydell, J., Fearon, P., Craig, T.K., Dazzan, P., \& Morgan, K. (2014). Interplay Between Childhood Physical Abuse and Familial Risk in the Onset of Psychotic Disorders. Schizophrenia Bulletin, 40, 1443-1451.

Frith, U., \& Vignemont, F. (2005). Egocentrism, allocentrism, and Asperger syndrome. Consciousness and Cognition, 14, 719-738.

Giese, A.A., Thomas, M.R., \& Dubovsky, S.L. (1997). Dissociative symptoms in psychotic mood disorders: an example of symptom nonspecificity. Psychiatry, 60, 60-6.

Gil, A., Gama, C.S., de Jesus, D.R., Lobato, M.I., Zimmer, M., \& Belmonte-de-Abreu, P. (2009). The association of child abuse and neglect with adult disability in schizophrenia and the prominent role of physical neglect. Child Abuse \& Neglect, 33, 618-624.

Grotstein, J.S. (1977a). The Psychoanalytic Concept of Schizophrenia: I. the Dilemma. International Journal of Psychoanalysis, 58, 403-425.

Grotstein, J.S. (1977b). The Psychoanalytic Concept of Schizophrenia: II. Reconciliation. International Journal of Psychoanalysis, 58, 427-452.

Hasson-Ohayon, I. (2012). Integrating cognitive behavioral-based therapy with an inter-subjective approach: Addressing metacognitive deficits among people with schizophrenia. Journal of Psychotherapy Integration, 22, 356-374.

Hillis, J.D., Leonhardt, B.L., Vohs, J.L., Buck, K.D., Salvatore, G., Popolo, R., Dimaggio, G., \& Lysaker, P.H. (2015). Metacognitive reflective and insight therapy for people in early phase of a schizophrenia spectrum disorder. Journal of Clinical Psychology, 71, 125-35. 
Hinshelwood, R.D. (2008). Repression and Splitting: Towards a method of conceptual comparison. International Journal of Psychoanalysis, 89, 503-521.

Janssen, I., Krabbendam, L., Bak, M., Hanssen, M., Vollebergh, W., de Graaf, R., \& van Os, J. (2004). Childhood abuse as a risk factor for psychotic experiences. Acta Psychiatrica Scandinavica, 109, 38-45.

Jung, C.G. (1909). The Psychology of Dementia Praecox. New York: The Journal of Nervous and Mental Disease Publishing Company.

Kukla, M., Lysaker, P.H., \& Salyers, M.P. (2013). Do persons with schizophrenia who have better metacognitive capacity also have a stronger subjective experience of recovery? Psychiatry Research, 209, 381-5.

Larrson, S., Andreassen, O.A., Aas, M., Røssberga, J.I., Mork, E., Steen, N.E., Barrett, E.A., Lagerberg, T.W., Peleikis, D., Agartz, I., Melle, I., \& Lorentzen, S. (2013). High prevalence of childhood trauma in patients with schizophrenia spectrum and affective disorder. Comprehensive Psychiatry, 54, 123-127.

Lustman, J. (1977). On Splitting. Psychoanalytic Study of the Child, 32, 119-153.

Lysaker, P.H., Buck, K.D., \& Ringer, J. (2007). The recovery of metacognitive capacity in schizophrenia across 32 months of individual psychotherapy: A case study. Psychotherapy Research: Journal of the Society for Psychotherapy Research, 17, 713-720.

Lysaker, P.H., \& Larocco, V.A. (2008).The prevalence and correlates of trauma-related symptoms in schizophrenia spectrum disorder. Comprehensive Psychiatry, 49, 330-334.

Lysaker, P.H., \& Salyers, M.P. (2007). Anxiety symptoms in schizophrenia spectrum disorders: associations with social function, positive and negative symptoms, hope and trauma history. Acta Psychiatrica Scandinavica, 116, 290-298.

Lysaker, P.H., Meyer, P.S., Evans, J.D., Clements, C.A., \& Marks, K.A. (2001). Childhood sexual trauma and psychosocial functioning in adults with schizophrenia. Psychiatric Services, 52, 1485-1488.

Lysaker, P.H., Clements, C.A., Hallberg, C.P., Knipschure, S.J., \& Wright, D.E. (2002). Insight and personal narratives of illness in schizophrenia. Psychiatry, 65, 197-206.

Lysaker, P.H., Nees, M.A., Lancaster, R.S., \& Davis, L.W. (2004). Vocational function among persons with schizophrenia with and without history of childhood sexual trauma. Journal of Traumatic Stress, 17, 435-438.

Lysaker, P.H., Carcione, A., Dimaggio, G., Johannesen, J.K., Nicolò, G., Procacci, M., \& Semerari, A. (2005a). Metacognition amidst narratives of self and illness in schizophrenia: associations with insight, neurocognition, symptom and function. Acta Psychiatrica Scandinavica, 112, 64-71.

Lysaker, P.H., Davis, L.D., Eckert, G.J., Strasburger, A.M., Hunter, N.L., \& Buck, K.D. (2005b). Changes in narrative structure and content in schizophrenia in long term individual psychotherapy: A single case study. Clinical Psychology and Psychotherapy, 12, 406-416.

Lysaker, P.H., Dimaggio, G., Buck, K.D., Carcione, A., \& Nicolò, G. (2007). Metacognition within narratives of schizophrenia: Associations with multiple domains of neurocognition. Schizophrenia Research, 93, 278-287.

Lysaker, P.H., Warman, D.M., Dimaggio, G., Procacci, M., Larocco, V.A., Clark, L.K., Dike, C.A., \& Nicolò, G.. (2008). Metacognition in prolonged schizophrenia: Associations with multiple assessments of executive function. The Journal of Nervous and Mental Disease, 196, 384-389.

Lysaker, P.H., Dimaggio, G., Carcione, A., Procacci, M., Buck, K.D., Davis, L.W., \& Nicolò, G.. (2010a). Metacognition and schizophrenia: The capacity for self-reflectivity as a predictor for prospective assessments of work performance over six months. Schizophrenia Research, 122, 124-130.

Lysaker, P.H., Dimaggio, G., Daroyanni, P, Buck, K.D., LaRocco, V.A., Carcione, A., \& Nicolò, G. (2010b). Assessing metacognition in schizophrenia with the Metacognition Assessment Scale: Associations with the Social Cognition and Object Relations Scale. Psychology and Psychotherapy, 83(Pt 3), 303-15.

Lysaker, P.H., Shea, A.M., Buck, K.D., Dimaggio, G., Nicolò, G., Procacci, M., Salvatore, G., \& Rand, K.L. (2010c). Metacognition as a mediator of the effects of impairments in neurocognition on social function in schizophrenia spectrum disorders. Acta Psychiatrica Scandinavica, 122, 405-413.

Lysaker, P.H., Buck, K.D., Caricione, A., Procacci, M., Salvatore, G., Nicolò, G., \& Dimaggio, G. (2011a). Addressing metacognitive capacity for self reflection in the psychotherapy for schizophrenia: A 
conceptual model of the key tasks and processes. Psychology and Psychotherapy Theory Research and Practice, 84, 58-69.

Lysaker, P.H., Erickson, M.A., Buck, B., Buck, K.D., Olesek, K., Grant, M.L., Salvatore, G., Popolo, R., \& Dimaggio, G. (2011b). Metacognition and social function in schizophrenia: Associations over a period of five months. Cognitive Neuropsychiatry, 16, 241-55.

Lysaker, P.H., Erickson, M.A., Ringer, J., Buck, K.D., Semerari, A., Carcione, A., \& Dimaggio, G.. (2011c). Metacognition in schizophrenia: the relationship of mastery to coping, insight, self-esteem, social anxiety, and various facets of neurocognition. The British journal of Clinical Psychology, 5, 412-424.

Lysaker, P.H., McCormick, B.P., Snethen, G., Buck, K.D, Hamm, J.A., Grant, M., Nicolò, G., \& Dimaggio, G. (2011d). Metacognition and social function in schizophrenia: Associations of mastery with functional skills competence. Schizophrenia Research, 131, 214-218.

Lysaker, P.H., Ringer, J.M., Buck, K.D., Grant, M., Olesek, K., Leudtke, B.L., \& Dimaggio, G. (2012). Metacognitive and social cognition deficits in patients with significant psychiatric and medical adversity: a comparison between participants with schizophrenia and a sample of participants who are HIV-positive. The Journal of Nervous and Mental Disease, 200, 130-134.

Lysaker, P.H., Bob, P., Pec, O. Hamm, J., Kukula, M., Vohs, J., Popolo, R., Salvatore, G., \& Dimaggio, G. (2013). Synthetic metacognition as a link between brain and behavior in schizophrenia. Translational Neuroscience, 4, 368-377.

Martens, W.H. (2009). The role of self-complexity in reducing harmful insight among persons with schizophrenia. Theoretical and therapeutic implications. American Journal of Psychotherapy, 63, 53-68.

McLeod, H.J., Gumley, A.I., Macbeth, A., Schwannauer, M., \& Lysaker, P.H. (2014). Metacognitive functioning predicts positive and negative symptoms over 12 months in first episode psychosis. Journal of Psychiatric Research, 54, 109-15.

Morrison, A.P., Frame, L., \& Larkin, W. (2003). Relationships between trauma and psychosis: A review and integration. British Journal of Clinical Psychology, 42, 331-353.

Moskowitz, A. (2008). Association and dissociation in the historical concept of schizophrenia. In: Moskowitz, A., Schafer, I., \& Dorahy,. M. (Eds.), Psychosis, Trauma, and Dissociation, pp.35-50. West Sussex: John Wiley and Sons.

Moskowitz, A., Read, J., Farrelly, S., Rudegeair, T., \& Williams, O.(2009). Are psychotic symptoms traumatic in origin and dissociative in kind? In: Dell, P.F., \& O'Neil, J.A. (Eds.). Dissociation and the dissociative disorders. DSM-V and beyond, pp.521-533. New York: Routledge.

Nabors, L.M., Yanos, P.T., Roe, D., Hasson-Ohayon, I., Leonhardt, B.L., Buck, K.D., \& Lysaker, P.H. (2014). Stereotype endorsement, metacognitive capacity, and self-esteem as predictors of stigma resistance in persons with schizophrenia. Comprehensive Psychiatry, 55, 792-798.

Nicolò, G., Dimaggio, G., Popolo, R., Carcione, A., Procacci, M., Hamm, J., Buck, K.D., Pompili, E., Buccione, I., Lagrotteria, B., \& Lysaker, P.H. (2012). Associations of metacognition with symptoms, insight, and neurocognition in clinically stable outpatients with schizophrenia. The Journal of Nervous and Mental Disease, 200, 644-647.

Nurcombe, B., Scott, J.G., \& Jessop, M.E. (2009). Dissociative hallucinosis. In: Dell, P.F., O’Neil, J.A. (Eds.) Dissociation and the dissociative disorders. DSM-V and beyond, pp.547-555. New York: Routledge.

Ogden, T.H. (1989). On the Concept of an Autistic-Contiguous Position. International Journal of Psychoanalysis, 70, 127-140.

Perona-Garcelan, S., Cuevas-Yust, C., Garcia-Montes, J.M., Pérez-Alvarez M, Ductor-Recuerda, M.J., Salas-Azcona, R., Gómez-Gómez, M.T., Rodríguez-Martín, B. (2008). Relationship between selffocused attention and dissociation in patients with and without auditory hallucinations. Journal of Nervous and Mental Disease, 196, 190-197.

Putnam, F.W., Carlson, E.B., Ross, C.A., Anderson, G., Clark, P., Torem, M., Bowmann, E., Coons, P., Chu, J.A., Dill, D.L, Loewenstein, R.J., \& Braun, B.G. (1996). Patterns of dissociation in clinical and nonclinical samples. Journal of Nervous and Mental Disease, 11, 673-679.

Read, J., Perry, B.D., Moskowitz, A., \& Connolly, J. (2001). The contribution of early traumatic events to schizophrenia in some patients: a traumagenic neurodevelopmental model. Psychiatry, 64, 319-345. 
Read, J., van Os, J., Morrison, A.P., \& Ross, C.A. (2005). Childhood trauma, psychosis and schizophrenia: a literature review with theoretical and clinical implications. Acta Psychiatrica Scandinavica, 112, 330350.

Renard, S.B., Pijnenborg, M., \& Lysaker, P.H. (2012). Dissociation and social cognition in schizophrenia spectrum disorder. Schizophrenia Research, 137, 219-223.

Roder, V., Mueller, D.R., \& Schmidt, S.J. (2011). Effectiveness of Integrated Psychological Therapy (IPT) for Schizophrenia Patients: A Research Update. Schizophrenia Bulletin, 37 (suppl. 2), S71-S79.

Rosenbaum, B., Harder, S., Knudsen, P., Køster, A., Lindhardt, A., Lajer, M., Valbak, K., \& Winther, G.. (2012). Supportive psychodynamic psychotherapy versus treatment as usual for first-episode psychosis: two-year outcome. Psychiatry, 75, 331-341.

Ross, C.A. (2009). The theory of dissociative subtype of schizophrenia. In: Dell, P.F., \& O’Neil JA (Eds.). Dissociation and the dissociative disorders. DSM-V and beyond, pp.557-568. New York: Routledge.

Ross, C., Anderson, G., \& Clark, P. (1994). Childhood abuse and positive symptoms of schizophrenia. Hospital \& Community Psychiatry, 45, 489-491.

Roy, A. (2005). Reported childhood trauma and suicide attempts in schizophrenic patients. Suicide and Life Threatening Behavior, 35, 690-693.

Sar, V., Taycan, O., Bolat, N., Briken, P., Lehmann, M., Moritz, S., Read, J., \& Naber, D. (2010). Childhood trauma and dissociation in schizophrenia. Psychopathology, 43, 33-40.

Schafer, I., Fisher, H.L., Aderhold, V., Huber, B., Hoffmann-Langer, L., Golks, D., Karow, A., Ross, C., Read, J., \& Harfst, T. (2012). Dissociative symptoms in patients with schizophrenia: relationships with childhood trauma and psychotic symptoms. Comprehensive Psychiatry, 53, 364-371.

Semerari, A., Carcione, A., Dimaggio, G., Falcone, M., Nicolò, G., Procacci, M., \& Alleva, G. (2003). How to evaluate metacognitive function in psychotherapy? The metacognition assessment scale and its applications. Clinical Psychology \& Psychotherapy, 10, 238-261.

Semerari, A., Carcione, A., Dimaggio, G.,Nicoló, G., Pedone, R., \& Procacci, M. (2005). Metarepresentative functions in borderline personality disorders. Journal of Personality Disorders, 19, 690-710.

Spitzer, C., Haug, H.J., \& Freyberger, H.J. (1997). Dissociative symptoms in schizophrenic patients with positive and negative symptoms. Psychopathology, 30, 67-75.

Stepniak, B., Papiol, S., Hammer, C., Ramin, A., Everts, S., Hennig, L., Begemann, M., \& Ehrenreich, H. (2014). Accumulated environmental risk determining age at schizophrenia onset: a deep phenotyping-based study. Lancet Psychiatry, 1, $444-453$.

Tas, C., Brown, E.C., Esen-Danaci, A., Lysaker, P.H., \& Brüne, M. (2012). Intrinsic motivation and metacognition as predictors of learning potential in patients with remitted schizophrenia. Journal of Psychiatric Research, 46, 1086-92.

Ucok, A., \& Bikmaz, S. (2007). The effects of childhood trauma in patients with first-episode schizophrenia. Acta Psychiatrica Scandinavica, 116, 371-377.

Van Donkersgoed, R.J., De Jong, S., Van der Gaag, M., Aleman, A., Lysaker, P.H., Wunderink, L., \& Pijnenborg, G.H. (2014). A manual-based individual therapy to improve metacognition in schizophrenia: protocol of a multi-center RCT. BMC Psychiatry, 3, 14-27.

Vogel, M., Spitzer, C., Barnow, S., \& Freyberger, H.J. (2006). The Role of Trauma and PTSD-Related Symptoms for Dissociation and Psychopathological Distress in Inpatients with Schizophrenia. Psychopathology, 39, 236-242.

Vogel, M., Schatz, D., Spitzer, C., Kuwert, P., Moller, B., Freyberg, H.J., \& Grabe, H.J. (2009a). A more proximal impact of dissociation than of trauma and posttraumatic stress disorder on schneiderian symptoms in patients diagnosed with schizophrenia. Comprehensive Psychiatry, 50, 128-134.

Vogel, M., Spitzer, C., Kuwert, P., Möller, B., Freyberger, H.J., \& Grabe, H.J. (2009b). Association of childhood neglect with adult dissociation in schizophrenic inpatients. Psychopathology, 42, 124-130.

Vohs, J., \& Lysaker, P.H. (2014). Metacognitive mastery and intrinsic motivation in schizophrenia. The Journal of Nervous and Mental Disease, 202, 74-77. 
Vohs, J.L., Lysaker, P.H., Francis, M., Hamm, J., Buck, K.D., Olesek, K., Outcalt, J., Dimaggio, G., Leonhardt, B., Liffick, E., Mehdiyoun, N., \& Breier, A. (2014). Metacognition, social cognition, and symptoms in patients with first episode and prolonged psychosis. Schizophrenia Research, 153, 54-9.

Walker, E.F., \& Diforio, D. (1997). Schizophrenia: a neural diathesis-stress model. Psychological Review, 104, 667-685.

Zubin J, \& Spring B. (1977). Vulnerability - a new view of schizophrenia. Journal of Abnormal Psychology, $86,103-26$. 